\title{
Promoting Peer Feedback in Developing Students' English Writing Ability in L2 Writing Class
}

\author{
Sirikarn Kuyyogsuy ${ }^{1}$ \\ ${ }^{1}$ Graduate School of Human Sciences, Assumption University, Thailand \\ Correspondence: Sirikarn Kuyyogsuy, Graduate School of Human Sciences, Assumption University, Thailand.
}

Received: April 17, 2019

Accepted: June 24, 2019 Online Published: August 29, 2019

doi:10.5539/ies.v12n9p76

URL: https://doi.org/10.5539/ies.v12n9p76

\begin{abstract}
The study aimed at investigating the effects of peer feedback on students' English writing ability in L2 writing class. A mixed-methods research, an embedded experimental design was employed, making use of a writing pretest and post-test and self-written reflection in the experiment. Data were quantitatively analyzed through a dependent simple t-test, and content was thematically analyzed for qualitative data. The participants were 21 undergraduate students majoring in English in the three southernmost border provinces of Thailand. The findings revealed that from the mean scores of the pretest and post-test, the students had made significant progress in their writing ability. Additionally, the effect size was calculated at 1.97, which means that its magnitude was "large". Moreover, students reflected that peer feedback was a worthwhile experience for social interaction, and provided them with perceiving the writing process, developing affective strategies, supporting critical thinking skills, and developing socially and intellectually by means of working collaboratively. In addition, it helped them practice to become more autonomous learners. As a result, peer feedback should be implemented in L2 writing classes.
\end{abstract}

Keywords: peer feedback, writing ability, L2 writing

\section{Introduction}

Writing is one of the productive skills which are paid much attention to, and it is widely accepted as a complex process for second language learners to achieve the perfect written tasks. The significance of English writing skills has been intensively focused for long time, and the teaching and learning process in a writing class does not seem to enable students, especially in ESL/EFL writing contexts, to become more efficient writers. Additionally, the teaching approaches do little to enhance the overall quality of students' writing, so this is hard work required to improve both the quality of writing and writing instruction by means of commenting, suggesting, providing good quality feedback in an attempt to help learners effectively increase their writing competence. At present, changes in writing strategies have transformed feedback practices from using teacher feedback often supplemented with also peer feedback; therefore, adopting peer feedback is a crucial component in multi-drafts process oriented in the writing instructions in L2 writing (Khalil, 2018).

According to peer feedback, it has been considered as the way of involving students in process of sharing ideas, providing and receiving constructive feedback to improve their writing skills (Farrah, 2012). Moreover, it has been pedagogically determined as an effective method to develop students' writing performance. There are a great deal of the advantages of employing peer feedback in L2 writing because peer feedback helps boost students' confidence and promotes their critical thinking skills in the act of reading texts commented by peers (Ferris, 1995). Additionally, peer feedback helps encourage students' learning motivation and to enhance social interaction skills because peer feedback is determined as a social practice that has an impact on students' behavior in stimulating them in the activity (Koka \& Hein, 2006). Moreover, peer feedback is theoretically advocated by the teaching and learning framework in the aspects of cooperative and collaborative learning, social interaction and L2 linguistic acquisition (Olsen \& Kagan, 1992; Oxford, 1997, cited in Kunwongse, 2013). Besides, it also activates self-awareness of their learning of strengths and weaknesses as Tsui and $\mathrm{Ng}$ (2000) reported, and it supports students with increasing the level of their responsibility for their own learning and autonomy (Morgan, 2002). In addition, students profit from the worthwhile experiences from conducting peer feedback and learning to each other; furthermore, it helps students practice their commutative skills and accept the different perspectives; listening attentively, thinking critically and taking constructively part in the activity (White \& Caminero, 1995, cited in Farrah, 2012). 
Although there are many positive viewpoints of peer feedback, utilizing peer feedback in ESL/EFL writing classes should be cautiously taken into teachers' consideration because there are some studies noting that students prefer adopting teacher feedback to peer feedback in classes. For instance, the peer-involved activity is time-consuming because learners are not familiar with the process. Peer feedback is a lengthy process, for learners have to spend much time reading drafts, taking notes, collaborating with another reader to achieve a consensus by means of giving a written commentary or engaging orally with the writer in a feedback circle, which consumes quite some time as Rollinson (2005) claimed. Additionally, the findings of Speck's (2000) study revealed that students still lack the necessary skills and appropriate level of confidence to evaluate or criticize peers' writing. Furthermore, students favor the teacher's comments to peer feedback since they still lack confidence on critiquing peers' tasks and have their own linguistic limitations. Moreover, there is the familiarity and belief that the teacher possesses all knowledge to provide better qualified feedback; in addition, some students misunderstand about the concept of peer feedback and do not know how to properly provide peer correction (Chen \& Lin, 2008; Ferris, 2002; Hyland \& Hyland, 2006; Tang \& Tithecott, 1999, cited in Kunwongse, 2013). Nevertheless, while comparing the benefits and drawbacks of peer feedback use, the findings of various studies displayed that students accepted the advantages rather than the disadvantages in doing peer feedback as concluded by Van Zundert et al.'s (2010) study.

In addition, many studies highlighted that peer feedback has been more increasingly adopted in L2 writing classes because the process of peer feedback has been proved as an effective pedagogical tool to develop students' writing skills (Corbin, 2012). However, referring to the Thai educational context, it has intensively focused on a teacher-centered approach, which places emphasis on the pivotal role dominated by teachers. This situation inevitably produces the spoon-feeding teaching style and strictness of the teaching process to the students. Nonetheless, to maximize students' learning motivation, peer feedback has become a worthy and interesting activity, which has helped teachers alter the learning practice in the way of emphasizing about the role of the students. Consequently, the overarching aim of this study involved students' development of their writing skills through peer feedback in an attempt to measure their progress while writing. Therefore, the research question attempted to investigate the effects of incorporating peer feedback to improve students' English writing conducted in an EFL tertiary writing class in the three southernmost border provinces of Thailand.

\section{Literature Review}

The significance of feedback in language learning is ordinarily discovered with widespread agreement in the field of English language teaching with attempt to develop students' written tasks. Written feedback is the crucial tasks for writing teachers to evaluate students' written performance to lead them to production quality improvement. Written feedback is considered as the input from a reader to a writer, which delivers information to the author for revision covering the comments, questions, and suggestions proposed by a reader, and the writer is able to revise the original in ways of adding more information, reinforcing logical organization, clarifying the development of ideas, or correcting word choice or tense (Keh, 1990, cited in Lei, 2017). In an EFL writing class, there are four types of feedback: teacher feedback, peer evaluation, self-assessment and cyber based revision, of which teacher feedback has been a tradition employed for many years. With the approach of the writing process, peer feedback has become a more increasingly vital component in a writing class owing to advocating student-centered learning (Lei, 2017). Peer feedback is classified under several names such as peer critique, peer review, peer revision, peer response, peer editing and peer evaluation, which is defined as a collaborative learning activity providing language learners to exchange their drafts and offer feedback to each other for the objective of revision (Mangelsdorf, 1992, cited in Lei, 2017). Peer feedback can be either provided in the form of a written or oral mode, or synchronous or asynchronous mode; moreover, it has been seen as a crucial feedback delivery system in process-based second language writing classes. More importantly, several studies have affirmed the positive effects of peer feedback toward the development of ESL/EFL writing contexts (Austria, 2017; Brusa \& Harutyunyan, 2019; Graham, 2010; Khalil, 2018; Kunwongse, 2013; Lam, 2010; Min, 2016; Rollinson, 2005).

\subsection{Benefits and Drawbacks of Peer Feedback Toward Teaching and Learning}

Many researchers have reported that peer feedback can be valued as an effective hands-on learning experience because it helps increase students' writing competence in a way of permitting them to take the role of the authors and reviewers whose task is to offer feedback to their peers' tasks (Hansen \& Liu, 2005; Lam, 2010). Moreover, peer feedback is widely believed to be beneficial to students in developing their writing, for it is timely and more informative, which are crucial components for their active engagement in offering feedback giving them a voice in scaffolding and constructing their own ability and eventually sharing their ideas (Lu \& Law, 2012; Reynolds, 
2009). Additionally, peer feedback has received importance for the potential of developing students' learning from various researchers in L2 writing (Hu, 2005; Lam, 2010; Min, 2016). For example, peer feedback provides students with multiple sources of constructive feedback; the recursive process of peer feedback also raises self-awareness, builds confidence, increases motivation, boosts their critical thinking skills, and supports their social skills (Farrah, 2012; Hirose, 2008; Orsmond et al., 2013). In addition, the role of the peer feedback process allows students to be the main actor and modeler for their learning process; this helps students develop learner autonomy more effectively and achieves higher levels of critical thinking; furthermore, it assists learners to develop critical reflection skills, learn to listen, evaluate adopting clear criteria and offer good quality feedback. Students as the assessees also learn through metacognitive processes; such as, reflection and the ability to justify their products, and accepting or rejecting suggestions including using their own argumentation (Liu \& Carless, 2006, cited in Brusa \& Harutyunyan, 2019).

In spite of the perceived benefits, several studies found that there were still some negative perspectives toward peer feedback use. As Rollinson (2005) mentioned, the peer activity is so time-consuming when the learners are not familiar with the peer feedback process because the process is very length with covering reading and making notes, collaborating with another reader to reach a consensus, and giving a written commentary or being involved orally with the writer that takes a significant amount of time. Furthermore, students' failure of conducting peer feedback may be due to the frustrating feedback conveyed to the student writer when the student readers deliver their information. Hence, this is the reasons for the need of peer feedback training (Min, 2005), time limitations (Leki, 1991), and the qualified feedback and credibility on peer response (Torwong, 2003). As a result, intensive peer training is imperative to practice students to become qualified informants in both providing and receiving feedback on the critique of their compositions. Additionally, the importance of peer feedback has been immensely focused on L2 learning theories with changes in communicative language teaching and the process approach to writing with moving a teacher-centered classroom into a student-centered classroom.

Nonetheless, when comparing with the benefits and drawbacks of peer feedback, its benefits have been obviously outweighed as several studies confirmed (Lam, 2010; Van Zundert et al., 2010). In short, there is no denying that peer feedback has a great deal of potential for the development of ESL/EFL students to increase their writing abilities despite having some disadvantages. However, in an attempt to display the advantages of the use of peer feedback in L2 writing, in the present study, written reflections were designed to explore students' perceptions toward peer feedback in increasing their writing ability; this particularly assisted students to obtain the full benefits from the activity and simultaneously helped teachers learn about students' learning barriers by preparing further guidance for future teaching to get them to learn how to perform in subsequent writing tasks. Hence, it is necessary for teachers to update themselves and keep up with the changes in order to adapt themselves to develop and change the system through employing written reflections in the teaching and learning processes (Tosuncuoglu, 2019).

\subsection{Writing Process}

The process of the writing approach is perceived as the development of written tasks as the whole process from the beginning to the final draft (White \& Arndt, 1991). It is imperative for writing teachers to understand how the writing process works to help students maximize their problem-solving skills when they are involved in each stage. In this study, the writing process was divided into six stages: Preparation, Drafting, Evaluating, Interactive back-feedback, Reviewing and Revising, which were adapted from Flower and Hayes (1981), White and Arndt (1991) and Kim (2005)'s conceptual frameworks. These stages are explained as follows: 1) Preparation: students were asked to compose a paragraph by generating their ideas, mind-mapping or conducting an outline, and using grammatical structure. 2) Drafting: students conveyed all of their thoughts into a written paragraph. 3) Evaluation: students conducted a peer group activity by evaluating their peers' work through discussion. 4) Interactive-back feedback: the student writer could immediately ask for clarification of the errors if they disagreed with their peers' response. 5) Reviewing: students monitored their work by self-assessment. 6) Revising: students were asked to rewrite their paragraph including checking grammar use and handwriting. With regards to the students' roles in doing peer feedback, students take the responsibility of their roles as the assessors and assessees. As the assessors, they evaluate their peer's task by providing feedback while as the assessees, they take the role of the students who obtain feedback and instantaneously discuss if they object to their peers' responses (Kim, 2005).

\section{Methodology}

\subsection{Research Design}

The researcher employed the embedded experimental model of a mixed-methods research of which a qualitative 
method was embedded in a quantitative experiment to reinforce the experimental design (Creswell, 2011). Data were quantitatively collected by means of a pre-posttest of writing and written reflection was qualitatively used.

\subsection{Participants}

The study was carried out in the 2018 academic year. The participants were 21 third-year English majors in a university in the three southernmost border provinces of Thailand. They were required to participate in a writing class for approximately 11 weeks. They already had basic English knowledge because they had finished two years of English courses, which covered English Structure I, English Structure II, Writing I and Writing II. As a result, this implied that they had sufficient English writing ability to provide feedback through a peer group activity.

\subsubsection{Context of the Study}

As part of a larger study about doing a peer-involved activity in L2 writing class, this study investigated the effects of using peer feedback in the writing of 21 Thai EFL university students. In reference to the students' backgrounds, they were all Muslims who had graduated from private religious schools. Specifically, they speak Pattani-Malay, which is a dialect in which Thai-Muslims use as their mother tongue. In regard to the Thai government, all of the public schools and universities are required to use Thai language for mother tongue-based education in mediating. Nevertheless, the students were permitted to use the dialect in case that they could not clarify the intended meaning or some information to their peers.

\subsection{Data Collection Tools}

For the first research tool, the writing pretest and post-test was adopted to measure students' English proficiency, and self-written reflections were employed as the second research tool after peer feedback session. The data were also collected to provide more insight into incorporating peer feedback to improve their L2 writing.

\subsubsection{Writing Test}

In the study, narrative paragraph writing was used as the pretest and post-test to investigate students' English writing competence. The evaluation criteria consisted of five major writing components: mechanics, language use, vocabulary, organization and content, which were based on Jacobs' (1981, cited in Haswell, 2005) scoring profile; each writing component was divided into four rating levels of "Very poor, Fair to poor, Good to average, and Very good to excellent". For the test, students were requested to write a narrative paragraph on the topic of "An Interesting Day Last Summer" of approximately 180-200 words. The test duration was for 1.30 hours, and they were allowed to use a dictionary in the exam if they wished.

\subsubsection{Self-Written Reflection}

To gain some insight into utilizing peer feedback in developing students' writing skills, self-written reflections were employed to explore what they had learned in conducting a peer group discussion. Reflective thinking has been more increasingly employed as a form of critical expression with its necessities in teachers' professional development as the important factor on reflective teaching in language teaching (Mann \& Walsh, 2017). This notion was used by the students who acted as student teachers in providing feedback to their peers. Furthermore, for the researcher to improve a better teaching performance, written reflection worksheets were distributed to students to reflect upon using peer feedback. The worksheet consisted of three main sections with nine questions. Section I investigated students' understanding about the writing process; students were requested to write the six stages of peer feedback by focusing on the details of each. Section II explored students' benefits and drawbacks of peer feedback, and Section III involved students' additional recommendations in conducting peer feedback in a writing course. The time duration for doing the written reflection was 20-30 minutes.

\subsection{Data Analysis}

To ensure inter-rater reliability, a dependent sample t-test was employed in the data analysis. The writing scores were given by two raters, which compared and analyzed the data by adopting normal distribution, correlation coefficient and a t-test. The data analysis showed correlations among the two raters' grading the students' pretest and post-test scores of writing quality; the Spearman's Rho correlation coefficient was 0.85 and 0.87 , respectively.

Referring to the self-written reflection, thematic content analysis was employed in the main method of the data analysis and interpretation in the present study. For the content validity, three English language experts who held a doctoral degree with several years of English teaching experience judged the guidelines of the written self-reflection for its congruence toward the objectives. The self-reflection guidelines were developed as comments and recommendations. The content was validated at 0.70 . To ensure the reliability, the inter-rater 
reliability was measured, and Pearson's correlation coefficient was 0.85 .

\subsection{Data Collection Procedure}

In the study, a writing pretest was used to measure students' prior English knowledge in the first week. Afterwards, the students were effectively trained how to construct a paragraph with the writing process, to provide feedback, to adopt peer feedback materials, and to conduct peer discussion. Peer feedback training took the first three weeks. In the following eight weeks, students studied about descriptive and narrative paragraph writing, and each week, heterogeneous groups of three members were formed to conduct peer feedback. Finally, students were asked to reflect upon the peer feedback through a self-written reflection. To measure students' English writing efficiency, they were required to do a writing post-test.

\subsubsection{Peer Feedback Training}

Before the peer feedback session, the teacher should realize the aspects to effectively implement peer feedback in a writing class on how to train students to adopt peer feedback effectively by having a well-managed plan (Hansen \& Liu, 2005). Hence, the concepts and guidelines from Min's (2005) four-step procedure and Lam's (2010) peer feedback training workshop were adapted as the aim of the study in an appropriate way.

The peer training lasted the first three weeks of the writing course. The peer feedback training was divided into three stages: modeling, exploring and consciousness-raising. Modeling Stage: The researcher introduced the peer group activity and explained about the purpose of adopting peer feedback in detail. Afterwards, the researcher highlighted the advantages of peer feedback and shared about the objectives of peer training to enable the students to have adequate revision skills to complete their tasks. Later, the researcher demonstrated the writing process, a four-step procedure; namely, clarifying, identifying, explaining and giving suggestions, as well as employing peer feedback checklists, and coding the five types of errors on the tasks. Exploring Stage: Students were required to do some exercises about the four-step procedure, five types of errors, and peer feedback checklists with some examples. This helped them to practice evaluate how well the students understood the use of the peer feedback materials. Next, they exchanged the tasks with their peers and discussed the errors. After that, seven students of each group were interviewed about what they had learned about the peer feedback materials. Consciousness-Raising Stage: As the last stage of the peer feedback training, students were required to produce a written narrative paragraph of about 150 words, and 21 students were divided into a group of three with mixed English proficiency. Peer feedback occurred naturally; however, if an assessee objected to a peer response, he/she suddenly debated and asked for clarifications about the grammatical mistakes from the readers. After completing the peer training, the students were requested to reflect upon adopting the peer feedback process.

\section{Results}

\subsection{Results of the Quantitative Data}

The results presented that the students' post-test writing scores were significantly higher than that of the pretest after the peer feedback session $(\mathrm{t}=25.89, \mathrm{p}<0.05)($ refer to Table 1$)$.

Table 1. Statistical test of the mean of the writing pretest and post-test

\begin{tabular}{lcccccccc}
\hline Writing Test & $\mathrm{N}$ & Mean & SD & Level & Mean Gain & t & df & Sig. (One-tailed) \\
\hline Pretest & 21 & 69.19 & 2.60 & Fair to Poor & \multirow{2}{*}{5.14} & 25.89 & 20 & .000 \\
Post-test & 21 & 74.33 & 2.62 & Good to Average & & & & \\
\hline
\end{tabular}

As Table 1 presented above, by examining the statistically significant differences between the pretest and the post-test writing scores, the results from the dependent sample t-test illustrated that students' mean scores of the writing post-test were $\mathrm{M}=74.33$, S.D $=2.62$, which indicated a level of 'Good to average'. This was significantly higher than the mean scores of the pretest at $\mathrm{M}=69.19, \mathrm{~S} . \mathrm{D}=2.60 \mathrm{in}$ a level of 'Fair to poor' with a significant difference at $\mathrm{p}=0.000$. The researcher also calculated the effect size of the magnitude of the peer feedback by adopting Cohen's d values. The value of eta squared was 1.97, which suggested a large effect (Cohen, 1988, cited in Pallant 2001). Cohen's d values and the interpretation for the magnitude of the effect were noted as $d=0.2$ that was considered a 'small' effect size, 0.5 represented a 'medium' effect size, and 0.8 a 'large' effect size. Thus, this illustrated that there was a large effect size with a substantial difference in students' writing performance scores before and after using peer feedback. In addition, this implied that peer feedback was a predictor of students' English writing improvement. Moreover, to analyze students' English writing with the 
five types of errors between the writing pretest and post-test, the dependent sample t-test was adopted to calculate the mean scores of each (refer to Table 2).

Table 2. Statistical comparison of the writing scores based on each category of the writing rubric

\begin{tabular}{cccccccccc}
\hline \multirow{2}{*}{ Criteria } & Writing Test & $\mathrm{N}$ & Mean & $\mathrm{SD}$ & Assessment & $\begin{array}{c}\text { Mean } \\
\text { Gain }\end{array}$ & $\mathrm{t}$ & $\mathrm{df}$ & Sig. (One-tailed) \\
\hline \multirow{2}{*}{ Mechanics } & Pre & 21 & 3.48 & .51 & Fair to Poor & 0.52 & 4.69 & 20 & .000 \\
& Post & 21 & 4.00 & .31 & Good to Average & & & & \\
Language use & Pre & 21 & 16.86 & 1.27 & Fair to Poor & 1.14 & 14.60 & 20 & .000 \\
& Post & 21 & 18.00 & 1.18 & Good to Average & & & & \\
Vocabulary & Pre & 21 & 14.33 & .57 & Good to Average & 0.76 & 5.58 & 20 & .000 \\
& Post & 21 & 15.10 & .70 & Good to Average & & & & \\
Organization & Pre & 21 & 14.24 & .88 & Good to Average & 0.81 & 7.24 & 20 & .000 \\
& Post & 21 & 15.05 & .97 & Good to Average & & & & \\
& Pre & 21 & 20.29 & 1.23 & Fair to Poor & 1.81 & 20.60 & 20 & .000 \\
\hline
\end{tabular}

As Table 2 presented, the results showed that there were statistically significant differences at $p=0.000$ on the five types of error categories. This demonstrated that students' mean scores of each category in the writing pretest and post-test were 'Mechanics' $(\mathrm{M}=3.48, \mathrm{SD}=0.51: \mathrm{M}=4.00, \mathrm{SD}=0.31)$, 'Language use' $(\mathrm{M}=16.86$, $\mathrm{SD}=18.00: \mathrm{M}=18.00, \mathrm{SD}=1.18)$, 'Vocabulary' $(\mathrm{M}=14.33, \mathrm{SD}=0.57: \mathrm{M}=15.10, \mathrm{SD}=0.70)$, 'Organization' $(\mathrm{M}=14.24, \mathrm{SD}=0.88: \mathrm{M}=15.05, \mathrm{SD}=0.97)$, and 'Content' $(\mathrm{M}=20.29, \mathrm{SD}=1.23: \mathrm{M}=22.10, \mathrm{SD}=1.22 . \mathrm{To}$ elaborate, in the types of mechanics, language use and content, students performed their writing efficiency in the level of 'Fair to poor' in the writing pretest; however, after the writing course, students could improve their writing ability which was in the level of "Good to average" in the writing post-test. Subsequently, regarding the types of using vocabulary and content, students had prior English knowledge in the level of 'Good to average' in the writing pretest. Nevertheless, although the students were still in the same level of adopting the vocabulary and the organization produced in the writing post-test, this indicated that students' mean scores had increased in both types. As mentioned above, after the peer feedback session, students significantly improved their English writing in all error categories in the writing post-test.

\subsection{Results of the Qualitative Data}

For the self-written reflections, triangulation was utilized to raise the validity and reliability of the findings. The results illustrated that four major themes were extracted from analyzing the data: 1) Learning strategies about the writing process, 2) affective strategies, 3) critical thinking skills, and 4) students' beliefs and changes for writing improvement with the subthemes, categories as well as the frequency count and percentages (refer to Table 3 ). 
Table 3. Self-written reflections on peer feedback process

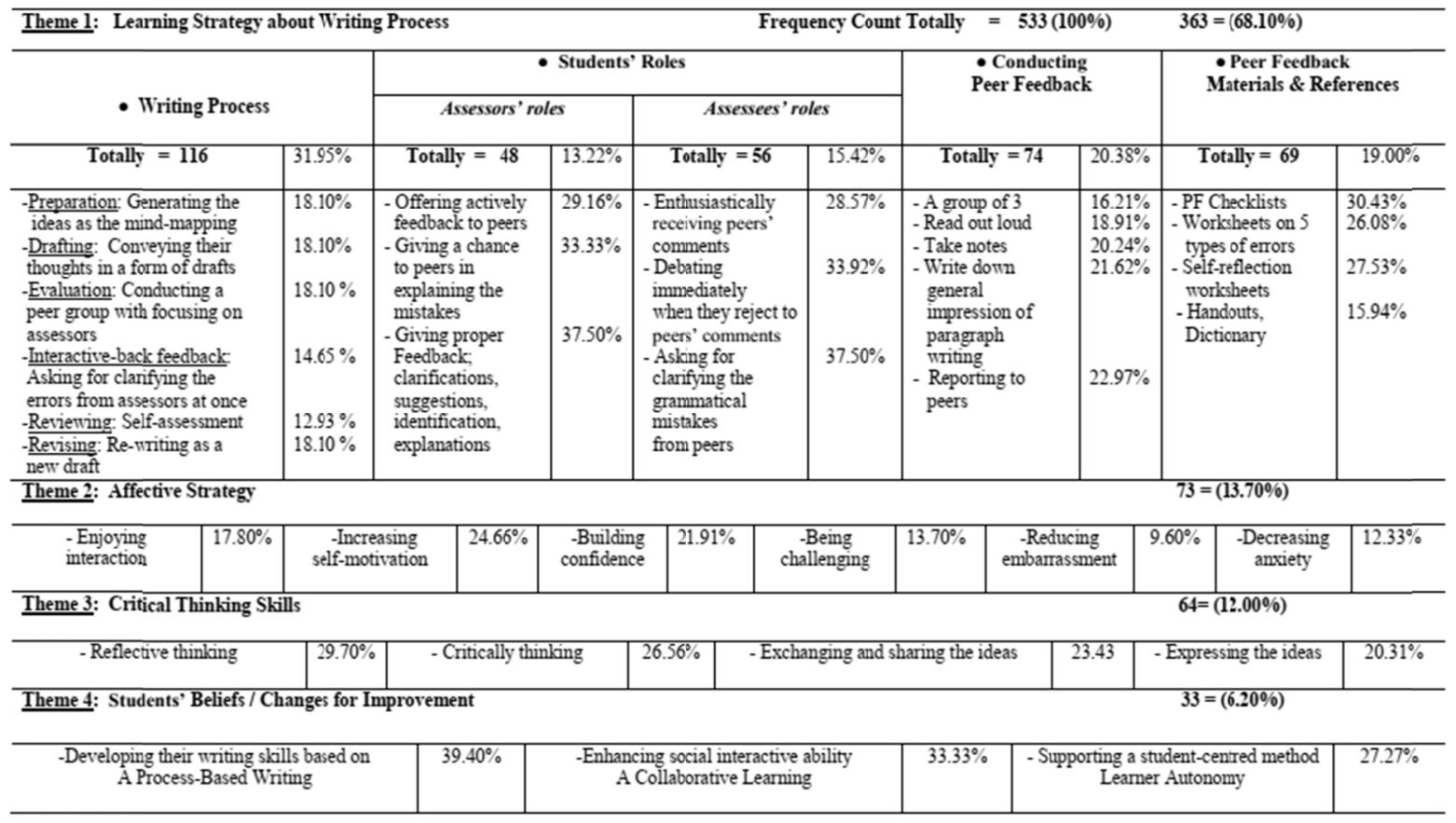

As Table 3 showed, the findings revealed that students had developed their writing ability through conducting peer feedback. Four main themes were extracted from the data in terms of the learning strategies about the writing and peer feedback processes, affective strategies, critical thinking skills, and students' beliefs and changes in their writing improvement. The first theme involved the approach of the writing process, which covered four subthemes as follows: six stages of peer feedback, the roles of the students, conducting group feedback, and peer feedback materials and references with its category. Overall, the findings of the first theme revealed that more than half of the students appreciated the learning strategies about the writing and peer feedback processes $(68.10 \%)$. This demonstrated that they perceived the use of the six stages of doing peer feedback $(31.95 \%)$; namely, preparation $(18.10 \%)$, drafting $(18.10 \%)$, evaluating $(18.10 \%)$, interactive-back feedback (14.65), reviewing (12.93\%) and revising (18.10\%). Secondly, regarding the roles of students in doing peer feedback (13.22\%), each student took two roles as both a feedback giver called an assessor and a feedback receiver called an assessee (33.33\%). As the assessors, this provided peers with more chances in explaining the errors and involving them in the peer activity and offering feedback such as clarifications, suggestions, identification and explanations $(37.50 \%)$. For the role as the assessees, they enthusiastically obtained peer editing (28.57), debated immediately when they objected to criticism (33.92\%), and asked for peers' clarifications and questions on the errors $(37.50 \%)$. Later, in conducting a peer group activity $(20.38 \%)$, they formed a peer group correctly such as working as a group of three (16.21\%), reading out (18.91\%), taking notes, (20.24\%), writing down some impressions of paragraph writing $(21.62 \%)$, and reporting to peers $(22.97 \%)$. Finally, students' understanding about the peer feedback materials and references (19\%); peer checklists $(30.43 \%)$, five types of errors $(26.08 \%)$, and self-written reflections $(27.53 \%)$ including the handouts and dictionary $(15.94 \%)$ were more effectively adopted in clarifying peers' written tasks.

With regards to students' feelings for the second theme in peer feedback use, the overall findings presented that students had positive feelings while conducting peer feedback $(13.69 \%)$. It obviously indicates that peer feedback helped students learn about affective strategies such as enjoying interactional comments $(17.80 \%)$, motivating them in learning $(24.65 \%)$, building confidence $(21.90 \%)$, and importantly, they noted that it helped decrease their embarrassment in giving face-to-face peer feedback $(9.58 \%)$ and writing anxiety $(12.32 \%)$.

For the increase of critical thinking skills as the third theme of doing peer feedback, the overall findings showed that students enhanced their critical thinking ability $(12 \%)$. It indicated that they improved their reflective thinking $(29.70 \%)$, critical thinking $(26.56 \%)$, exchanging and sharing ideas (23.43), as well as expressing ideas $(20.31 \%)$ in the peer discussion. As mentioned above, peer feedback practice facilitated the critical thinking ability through offering supportive feedback by peers.

With respect to the students' beliefs and changes for writing improvement as the last theme, overall the findings 
averaged $6.20 \%$. This implied that they perceived the learning strategies about process-based writing and peer feedback $(39.40 \%)$, and it enhanced their social interaction ability through collaborative learning $(33.33 \%)$ and supporting a student-centered classroom, and this encourages them become more autonomous learners (27.27\%).

\section{Discussion}

The study investigated the effects of peer feedback in improving students' English writing ability by using mixed-method research, an embedded experimental design. The quantitative data was used by means of a writing pretest and post-test whereas self-written reflections were qualitatively employed with obtaining a more comprehensive understanding through examining the role of the qualitative strand in mixed-method research (Creswell, 2011).

For the quantitative data, the results expressed that the writing pretest and post-test presented an improvement in students' writing ability. Overall, the findings of the categories in the writing rubrics demonstrated that there was a significant difference between the mean value of the Mechanics, Language Use, Vocabulary, Organization and Content scores compared to the pretest and post-test writing scores with the significance at $p=<0.05$. This indicated that students made progress on their writing ability by reducing the mistakes on each kind of error. This also corresponded to Tudor's (1996) study, which reported that students could improve their written tasks from correcting by peers. Besides, it was also in agreement with Corbin (2012)'s study, which reported the statistically significant differences between students' mean scores of the writing pretest and post-test. This apparently showed that students could develop their writing efficiency through peer feedback practice. Based on all error categories, in the writing pretest, students had a low writing efficiency at 'Fair to poor' through improving in the aspects of the Mechanics, Language use and Content. 1) Mechanics: students made frequent errors of spelling, capitalization, paragraphing with poor handwriting, and confusing the meaning of the sentence. 2) Language use: students had the problems about creating simple, compound and complex sentences; moreover, they made frequent errors of agreement, tense, word order, run-on sentences and using parts of speech, especially pronouns and prepositions. 3) Content: students had limited English knowledge of the subject with a few major and minor support details in the compositions and inadequate development of the topic. In the aspects of Vocabulary and Organization, the findings illustrated that students had basic English knowledge of using vocabulary and organizing in the level of 'Good to average'. 4) Vocabulary: there was a sufficient range of vocabulary, but the errors of word choice and idioms were still found in their texts 5) Organization: the main idea was quite clear; nevertheless, students still lacked the support details. In addition, it was found that students still produced text with a logical sequencing and development.

However, in the writing post-test, students significantly developed their writing skills with better improvement of all error categories. The results revealed that students were able to increase their level of writing efficiency in the use of Mechanics, Language Use and Content in the level at 'Good to average' after the teaching course. 1) Mechanics: students created the written work by reducing the errors of spelling, paragraphing, capitalization and punctuation, and the meaning was quite clear with having better handwriting. 2) Language use: students were more skilled in using compound and complex sentences. Several errors of agreement were reduced, and using tenses and word choice were better. They were also aware of using pronouns, prepositions, and articles, as well as decreased the errors in completing the sentences. Furthermore, fragments and run-ons were occasionally found in their writing. 3) Content: students logically developed their ideas more and produced a longer text within the allocated time. The supporting details were mostly related to the main idea. In the aspects of Vocabulary and Organization, students developed their writing skills in these aspects at 'Good to average' as the writing pretest presented earlier; this clearly showed that students could improve the vocabulary by increasing their mean scores. 4) Vocabulary: a diversity of vocabulary was adopted more increasingly, especially synonyms and antonyms to avoid using the same words. In addition, the sentences were found to be clear and meaningful, and the errors of word choices were reduced. 5) Organization: the main idea was clear; organizing and developing the logical sequencing were better than the writing pretest. In addition, the effect size was calculated at 1.97, which meant that the magnitude was 'large' with substantial potential to improve students' L2 writing efficiency. Therefore, peer feedback should be taken into consideration in the writing class.

With regards to the qualitative data, the results illustrated that students had positive views toward the practices and usefulness of incorporating peer feedback in a writing class. This was supported by the qualitative evidence through the self-written reflection, which noted that peer feedback was very helpful and beneficial to improve their written tasks more efficiently. This indicated that students perceived the writing and peer feedback processes, used peer feedback materials including the references more effectively, as well as took much responsibility on their roles. Moreover, it was found that the key element making them improve their compositions was influenced by the peer feedback training because it helped them appreciate the writing and 
peer feedback practice by going through the entire process of writing. Likewise, previous research asserted that peer feedback training had great potential in students' writing improvement (Hansen \& Liu, 2005). Additionally, this corresponded to Nguyen's (2016) study, which reported that peer training affected utilizing peer feedback in revising students' written tasks and raised their writing quality. Clearly, students need to be well-trained how to provide constructive feedback. As a consequence, success in conducting peer feedback is caused by the influence of having well-managed peer training. Moreover, a student with moderate English ability noted:

"Peer feedback was new to me, and I thought that it was rather difficult for me because I had no experience about using peer feedback before. However, I could perform it better. To conduct effective peer feedback, peer training is very crucial because I could learn about the strategies of the whole process of writing and peer feedback, the roles of the students, the use of peer feedback checklists and correcting peers' tasks by the use of correction symbols. Peer training helped me perceive a step-by-step process of writing and peer feedback." S1

Furthermore, the positive feelings were so imperative for students to lessen their stress and anxiety in the duration of doing peer feedback. This also raised self-motivation in engaging in the activity, and feeling the challenge of their English knowledge arising to peers in an attempt to improve their tasks. Therefore, continuous practice of conducting peer feedback would help reduce students' embarrassment, which in turn would build confidence in giving peer critiquing. Besides, this also conformed to Ferris's (1995) study that revealed students increased their self-confidence and could reinforce their critical thinking skills from reading texts provided by peers with similar written tasks. Likewise, it was also supported by Khalil's (2018) study, which proved that peer feedback motivated students to scrutinize peers' performance and engaged them in peer groups through taking personal responsibility and improving self-confidence in discussing with peers. Two students with low English proficiency mentioned:

"I felt so nervous and anxious when I got involved in the activity because peer feedback was new to me, and I disliked writing. Nevertheless, peer feedback training helped me decrease these concerns. Practicing writing and doing peer feedback weekly made me feel so relaxed and familiar with the use of the peer feedback materials. Pressure was reduced; in contrast, I was more confident to express ideas and to criticize peers' tasks. " S4

"In my opinion, I lacked confidence in providing feedback because I was poor in English grammar use. I was not confident to check the mistakes, but peer training helped me learn how to provide constructive feedback on peers' tasks and to deliver my messages to the peers. Importantly, routine practice of conducting peer feedback helped me dare to correct the compositions. I think that peer group feedback stimulated me to peer critiquing. I enjoyed writing more and more." S14

A student with high English proficiency expressed:

"This was my first experience about doing peer feedback. It was really challenging for me, and it motivated me in the activity. I wanted to compare my work with peers whether I was poor or good at English. Importantly, conducting peer feedback continuously increased my confidence in writing, and it made me more skillful in adopting the peer feedback materials. I enjoyed interacting with the peers. "S12

Another factor which was related to developing students' writing efficiency was increasing critical thinking skills, as getting involved in the activity enhanced their critical thinking by means of exchanging and sharing ideas with each other; the ideas were critically and analytically refined through peer discussion. As mentioned above, getting different ideas from peers helped students to sharpen their thinking abilities, as well as share their experiences and knowledge with each other. Consequently, critical thinking skills enhanced their competence to assess their tasks and become more critical revisers, and they could expand their logical longer texts with limited time. Clearly, students made outstanding progress in the content and organization in the test, and these corresponded with Min's (2005), Cai's (2011) and Shehadeh's (2011) studies, which reported that students' L2 writing can be developed; especially in the aspects of the content and organization through peer critiquing; on the other hand, the findings of Storch's (2005) and Cho and Schunn's (2007) studies, which reported that students significantly progressed on grammatical accuracy, complexity and put on lexical aspects by leaving aside the text's organization and content. However, in the current study, one student with moderate English competence positively stated:

"In my point of view, peer feedback provided me with more chances in expressing and sharing ideas. Furthermore, exchanging different experiences made me get new English knowledge. Moreover, discussing among the peer group members helped me think critically, and peer feedback encouraged me in a problem-solving activity. This helped me think logically and cautiously to convey information into my written drafts." S17 
Additionally, receiving feedback by peers made students learn to improve how to use grammar structure correctly, and to use punctuation and tenses on their tasks more efficiently; this also assisted them to improve their language use. They learned about new vocabulary, especially in the antonyms and synonyms to produce their written tasks to be more interesting. Moreover, they learned to avoid the common errors or notice them; spelling, capitalization, articles in improving in the mechanics. Providing feedback by peers helped students produce a paragraph with a decrease in the same mistakes which they had always made in subsequent writing tasks. This also coincided with Edge's (1989) and Makino's (1993) studies, which reported that students learned about the same mistakes that they always created by memorizing them from repetition from peers with an attempt to make their better writing tasks. However, referring to the surface changes and text-based changes, the findings displayed a majority of the students corrected the errors with the surface changes, but not meaning changes which brought new information into their tasks. In this regard, a student who had a high English ability mentioned:

"I sometimes thought that I did not trust peer evaluation, and I needed them to explain more details on the specific grammatical errors. Anyway, I accepted that peer discussion helped me gain more various ideas, I wanted clear feedback. I preferred teachers' comments." S19

In a peer group activity, the role of the assessors was similar to being student teachers practicing how to provide qualified feedback on peers' tasks. In group feedback, students could switch their roles in being both a feedback giver and a feedback receiver. Written reflections after conducting peer feedback were used every week such as reviewing their experiences about the writing strategies and peer feedback process, seeing their strengths and weaknesses on their own tasks, improving their writing performance and receiving peers' reflections helped them effectively practice the whole process of writing, and they could focus on the details provided by peers to improve their writing skills more effectively in the next class. As a consequence, critical reflective thinking has become a crucial factor in teachers' professional development. This is also in agreement with Mann and Walsh's (2017, p. 11) study, which addressed that "professional development is fundamentally a social process." That meant, doing reflective thinking through group peer feedback could help students better teaching performance in the ways of reviewing their past experiences, reading, improving their writing and having their well-prepared next teaching performance as student teachers. That meant, getting reflective thinking by peers helped them see their strengths and weaknesses via self-written reflections to improve their subsequent written tasks. Additionally, peer feedback is an effective method to facilitate students' cooperative learning, boosting self-confidence, expanding interaction, reinforcing critical thinking, and constructively engaging to the activity participation (Bolling, 1994). One student with a moderate English proficiency addressed:

"I think that the roles of the students helped me learn how to provide qualified feedback to peers' tasks and to develop my written performance. Certainly, I prepared myself in giving feedback with a well-prepared teaching performance. Moreover, I always reflected on my actions to see whether I had improved on what I did, and obtaining peers' reflections helped me to see my strengths and weaknesses as well." S8

With respect to students' beliefs and changes for their writing improvement as the last theme, overall students had a positive reflection upon utilizing peer feedback in a writing class. In creating their tasks, process-based writing was used more effectively, and the ideas were more logically sequenced. Self-assessment could be more correctly employed through the peer feedback checklists, and it also raised their self-awareness from evaluating their peers' tasks. In addition, the peer group activity enhanced their social interaction ability through collaborative learning. Learning and working collaboratively helped them learn how to suitably negotiate in delivering their messages to make the audiences appreciate their feedback through positive facial reactions and a clear voice. Most importantly, peer feedback supported the roles of the students; they could fully act on the critique of the tasks as evidenced in the findings of the qualitative data. However, other factors may be related to improving students' writing ability such as planning the lessons properly, practicing writing regularly and conducting peer feedback continuously. As claimed above, students enjoyed writing and became better skilled in doing peer feedback. All factors resulted in the improvement of students' English writing in the post-test. A student with moderate English efficiency noted:

"My writing was better; I was satisfied with it. When I got the topic from the teacher, process-based writing appeared in my mind. I could generate the various ideas as mind-mapping, and discussing helped me think more logically. I could develop socially through working collaboratively and learn how to maintain the group cohesion during the interaction. Additionally, I was less reliant on the teacher and learned how to solve the problems through self-assessment. The tactics that I received from the peer feedback trainings were very beneficial." S21 


\subsection{The Disadvantages of Peer Feedback}

With regard to students' obstacles in adopting peer feedback, there were some concerns that they faced in offering feedback. 1) Absenteeism was led to the failure of the use of peer feedback. 2) Time allocation was caused by the influence of providing specific and qualified feedback, for the students were still unfamiliar with peer feedback; such as, adopting peer feedback materials, or they were not skilled in correcting the errors with making use of the five types of error codes. 3) The closeness of the group peer members apparently affected students' providing and receiving feedback on peers' tasks, and a few students accepted that it was difficult to offer feedback to unfamiliar classmates since they were afraid that their peers would reject the peer evaluation; they preferred to avoid peers' conflict or arguments. 4) The unfriendly atmosphere in the interaction sometimes occurred through showing a negative facial reaction. These were the students' learning barriers in the peer feedback session from the start.

Nevertheless, continuous practice of conducting peer feedback could reduce the obstacles. 1) The roles of students in a peer group activity built their own responsibility to conduct effective peer feedback. 2) Doing peer feedback every week advocated their learning strategies. Students became more accustomed to adopting peer feedback materials to correct the errors on the compositions. 3) Working in group feedback established a closeness of the relationship to peer group members; therefore, they dared to provide honest feedback to peers' tasks. 4) A secure and collaborative atmosphere in peer discussion was effective through their proper use of voice and language. In this study, the students learned how to negotiate and compromise to reach a consensus through maintaining group cohesion and harmony. In other words, their voice was clearer with an appreciative volume to the audiences. In addition, among peer group members, it was more effectively conducted through their positive reactions and their willingness in giving and obtaining feedback. Accordingly, it ought to be noted that students could eliminate these problems to conduct peer feedback more effectively. More specifically, it corresponded with Grabe and Kaplan's (1996, p. 379) study, which addressed that peer feedback process enhanced students 'learning together', and it also helped students realize of how to use language for responding to others' written tasks. Moreover, peer feedback is a cooperative and collaborative learning activity reinforcing students to develop intrinsic motivation physically and mentally in learning by means of sharing information and their effort to achieve their tasks, develop trust with their peers, and to be responsible for their roles in participating in the activity (Frey \& Fisher, 2010; Olsen \& Kagan, 1992; Oxford, 1997; K. Williams \& C. Williams, 2012, cited in Kunwongse, 2013). As a consequence, incorporating peer feedback continually changed students' behavior into learning motivation in the writing class.

Although the efficacy of conducting peer feedback in L2 writing class remains argumentative among researchers, especially in EFL students with limited English competence as well as their preference of teachers' comments, increasing their writing competence through peer feedback practice resulted in the desired outcomes. This also demonstrated that peer feedback was so supportive and beneficial to all of the students even the students with a low English efficiency (Berg, 1999, cited in Wanchid, 2009). Moreover, this study also supported the advantages of using peer feedback of which many researchers had considered in L2 writing classes (Liu \& Hansen, 2002; Swain, 2006; Yu \& Lee, 2016; Zhu \& Mitchell, 2012).

In addition, students would be able to extend the practices and usefulness of learning strategies via peer feedback to listening, speaking and reading skills, or other relevant fields. Nevertheless, for further recommendations, peer feedback should be conducted in the semester of an EFL tertiary writing class to strengthen the findings, and more importantly, the numbers of the subjects should be cautiously taken into account in the issue of generalization.

\section{Conclusion and Implications}

The study aimed at developing students' English writing ability through peer feedback in a tertiary writing class. The results revealed that students improved their writing efficiency by having positive reflections toward peer feedback. This also motivated students to participate in the activity. Students' enjoyment in the process results in an effective product. In order for peer feedback to be effective, training is a crucial factor which enables students to improve their written performance with better grammar use. Additionally, written reflection helps them realize the fruitful advantages of adopting peer feedback, perceiving the writing process, developing affective strategies, enhancing reflective thinking and critical thinking skills, as well as reinforcing the ability of social interaction. Furthermore, it promotes language learner autonomy to write more frequently and accurately.

In addition, the findings provided pedagogical implications in an L2 writing class. 1) Peer feedback is an effective pedagogical tool, which can be adopted to the EFL/ESL writing contexts with an attempt to strengthen self-reliant students in supporting the learner-centered approach in the ways of permitting students to learn 
together and to develop socially and intellectually through peer group feedback; therefore, teachers can simultaneously encourage students to work independently through appropriate strategies by adopting the peer feedback materials. 2) Peer feedback strongly recommends that having well-managed training of peer feedback influences conducting peer feedback effectively, and peer feedback is considered as one of the motivational teaching materials, which is well-matched to the necessities of students to improve their writing skills and corresponds to a student-centered method, However, designing the lesson plans should be taken into account the students who are inexperienced about conducting peer feedback, and this could help teachers design the materials or activities of how to inspire students to participate in the activity. 3) The teaching of writing would succeed if students adopt peer feedback followed by teachers' comments and their written reflections. 4) The findings confirmed that the use of a well-structured collaborative activity through effective peer feedback resulted in an improvement in writing, and this was in relation to students' cultural background as well as their language use. 5) The results of this study were beneficial for testing students' language, so writing teachers could evaluate students in a collaborative peer activity in the duration of the semester instead of conducting unnecessary tests. As aforementioned, peer feedback ought to be implemented in an L2 writing class.

\section{References}

Austria, M. A. B. (2017). Peer Response as an Effective Writing Strategy. International Journal of Progressive Education, 13(2), 95-104.

Berg, E. (1999). Preparing ESL students for peer response. TESOL Journal, 8, 20-25.

Bolling, A. (1994). Using group journals to improve writing and comprehension. Journal on Excellence in College Teaching, 5(1), 47-55.

Brusa, M., \& Harutyunyan, L. (2019). Peer review: A tool to enhance the quality of academic written productions. English Language Teaching, 12(5). https://doi.org/10.5539/elt.v12n5p30

Cai, J. (2011). A contrastive study of on line peer feedback and online teacher feedback in teaching English writing to college students. Foreign Language World, 134(2), 65-72.

Chen, P., \& Lin, Y. (2008). The effect of peer-review and teacher-review in young NNS learners' guided writing instruction. Retrieved from http://ord.npue.edu.tw/ezcatfiles/b008/img/img/1300/E32- 10.pdf

Cho, K., \& Schunn, C. D. (2007). Scaffolded writing and rewriting in the discipline: A web-based reciprocal peer review system. Computers \& Education, 48, 409-426. https://doi.org/10.1016/j.compedu.2005.02.004

Cohen, J. (1988). Statistical power analysis for the behavioral sciences (2nd ed.). Hillsdale, NJ: Lawrence Earlbaum Associates.

Corbin, B. (2012). Improving L2 Peer Feedback. Retrieved from https://www.Bryancorbin.Net/2012/Improving-L2-P

Creswell, J. W. (2011). Controversies in Mixed Methods Research. In N. Denzin, \& Y. S. Lincoln (Eds.), The Sage Handbook of Qualitative Research (4th ed., pp. 269-283). Thousand Oaks, CA: Sage Publications.

Edge, J. (1989). Mistakes and correction. London: Longman.

Farrah, M. (2012). The impact of peer feedback on improving the writing skills among Hebron University students. An-Najah University Journal for Research, 26(1), 179-210

Ferris, D. (1995). Students reactions to teacher response in multiple draft composition classrooms. TESOL Quarterly, 29, 33-53. https://doi.org/10.2307/3587804

Ferris, D. (2002). Treatment of error in second language student writing. Ann Arbor, MI: University of Michigan Press.

Flower, L. (1979). Writer-Based Prose. A Cognitive Basis for Problems in Writing. College English, 41(1), 19-37. https://doi.org/10.2307/376357

Flower, L. S., \& Hayes, J. R. (1981). A cognitive process theory of writing. College Composition and Communication, 32, 365-387. https://doi.org/10.2307/356600

Frey, N., \& Fisher, D. (2010). Motivation Requires a Meaningful Task. English Journal, 100(1), 30-36.

Grabe, W., \& Kaplan, R. B. (1996). Theory \& practice of writing. London: Pearson Education.

Graham, S. (2010). Teaching writing. In P. Hogan (Ed.), Cambridge encyclopedia of language sciences (pp. 848-851). Cambridge, UK: Cambridge University Press. 
Hansen, J. G., \& Liu, J. (2005). Guiding principles for effective peer response. ELT Journal, 59(1), 31-38. https://doi.org/10.1093/elt/cci004

Haswell, R. (2005). Researching Teacher Evaluation of Second Language Writing. In T. Silva, \& P. K. Matsuda (Eds.), Second Language Writing Research: Perspectives on the Process of Knowledge Construction (pp. 105-120). London: Lawrence Erlbaum Associates.

Hirose, K. (2008). Cooperative learning in English writing instruction through peer feedback. Retrieved from https://jasce.jp/conf05/hirosepaper.doc

Hu, G. (2005). Using peer review with Chinese ESL student writers. Language Teaching Research, 9(3), 321-342. https://doi.org/10.1191/1362168805/r169oa

Hyland, K., \& Hyland, F. (2006).Feedback on second language students' writing. Lang. Teach., 39, 77-95. https://doi.org/10.1017/S0261444806003399

Jacobs, H. L. (1981). Testing ESL Composition: A Practical Approach. English Composition Program. Newbury House Publishers, Inc., Rowley, MA 01969.

Keh, C. L. (1990). Feedback in the writing process: A model and methods for implementation. ELT Journal, 44(4), 294-304. https://doi.org/10.1093/elt/44.4.294

Khalil, E. (2018). The efficacy of peer feedback in Turkish EFL students' writing performance. Journal of Literature and Art Studies, 8(6), 920-931. https://doi.org/10.17265/2159-5836/2018.06.011.

Kim, M. (2005). Peer Assessment as a Learning Method. The Effects of the Assessor and Assessee's Role on Metacognitive Awareness, Performance, and Attitude.

Koka, A., \& Hein, V. (2006). Perceptions of teachers' general and informational feedback and intrinsic motivation in physical education: two-year effects. Perceptual and Motor Skills, 103, 321e332. https://doi.org/10.2466/PMS.103.6.321-332

Kunwongse, S. (2013). Peer Feedback, Benefits and Drawbacks. Thammasat Review, Special Issue, 2013.

Lam, R. (2010). A peer review training workshop: Coaching students to give and evaluate peer feedback. TESL Canada Journal, 27(2), 114-127. https://doi.org/10.18806/tesl.v27i2.1052

Lei, Z. (2017). Salience of student written feedback by peer-revision in EFL writing class. English Language Teaching, 10(12), 151-157. https://doi.org/10.5539/elt.v10n12p151

Leki, I. (1991). The preference of ESL students for error correction in college-level writing classes. Foreign Language Annals, 24, 203-218. https://doi.org/10.1111/j.1944-9720.1991.tb00464.x

Liu, J., \& Hansen, J. (2002). Peer response in second language writing classrooms. Ann Arbor, MI: University of Michigan Press. https://doi.org/10.3998/mpub.8952

Liu, N. F., \& Carless, D. (2006). Peer feedback: The learning element of peer assessment. Teaching in Higher Education, 11(3), 279-290. https://doi.org/10.1080/13562510600680582

Lu, J., \& Law, N. (2012). Online Peer Assessment: Effects of Cognitive and Affective Feedback. Instructional Science: An International Journal of the Learning Sciences, 40(2), 257-275. https://doi.org/10.1007/s11251-011-9177-2

Makino, T.-Y. (1993). Learner self-correction in EFL written compositions. ELT Journal, 47(1), 337-341. https://doi.org/10.1093/elt/47.4.337

Mangelsdorf, K. (1992). Peer reviews in the ESL composition classrooms: What do the students think? ELT Journal, 46(3), 274-284. https://doi.org/10.1093/elt/46.3.274

Mann, S., \& Walsh, S. (2017). Reflective Practice in English Language Teaching: Research-Based Principles and Practices. New York: Routledge. https://doi.org/10.4324/9781315733395

Min, H. T. (2005). Training students to become successful peer reviewers. System, 33(2), 293-308. https://doi.org/10.1016/j.system.2004.11.003

Min, H. T. (2016). Effect of teacher modeling and feedback on EFL students' peer review skills in peer review training. Journal of Second Language Writing, 31, 43-57. https://doi.org/10.1016/j.jslw.2016.01.004

Morgan, S. (2002). Peer Review. English Teaching Professional, 38, 29-30.

Nguyen, H, T. (2016). Peer Feedback Practice in EFL Tertiary Writing Classes. English Language Teaching, 9(6), 76-91. https://doi.org/10.5539/elt.v9n6p76 
Nguyen, T. T. L. (2019). Implementing peer-feedback in paragraph-writing classes at a Thai university. In S. M. Anwaruddin (Ed.), Knowledge mobilization in TESOL: Connecting research and practice (1st ed., pp. 30-42). Leiden, The Netherlands: Brill. https://doi.org/10.1163/9789004392472_003

Olsen, R., \& Kagan, S. (1992). About cooperative learning. In C. Kessler (Ed.), Cooperative Language Learning: A teacher's Resource Book (pp. 1-30). Englewood Cliffs, NJ: Prentice Hall.

Orsmond, P., Maw, S. J., Park. R. J., Gomez, S., \& Crook, C. A. (2013). Moving feedback forward: Theory to practice. Assessment \& Evaluation in Higher Education, 38(2), 240-252. https://doi.org/10.1080/02602938.2011.625472

Oxford, R. L. (1997). Cooperative learning, collaborative learning, and interaction: Three communicative strands in the language classroom. The Modern Language Journal, 81(4), 443-456. https://doi.org/10.1111/j.1540-4781.1997.tb05510.x

Pallant, J. (2001). SPSS Survival Manual: A step by step guide to data analysis using SPSS for Windows (Version 10).

Reynolds, A. (2009). Why Every Student Needs Critical Friends. Educational Leadership, 67(3), 54-57.

Rollinson, P. (2005). Using peer feedback in the ESL writing class. ELT Journal, 59(1), 23-30. https://doi.org/10.1093/elt/cci003

Rovinelli, R. J., \& Hambleton, R. K. (1977). On the use of content specialists in the assessment of criterion-referenced test item validity. Dutch Journal of Educational Research, 2, 49-60.

Shehadeh, A. (2011). Effects and student perception of collaborative writing in L2. Journal of second language writing in L2, 20(4), 286-305. https://doi.org/10.1016/j.jslw.2011.05.010

Speck, B.W. (2000). Grading students' classroom writing: Issues and strategies (ASHE-ERIC Higher Education Report Vol. 27, No. 3). Washington, DC: The George Washington University, Graduate School of Education and Human Development).

Storch, N. (2005). Collaborative writing; Product, process, and students' reflections. Journal of Second Language Writing, 14(3), 153-173. https://doi.org/10.1016/j.jslw.2005.05.002

Swain, M. (2006). Language agency and collaboration in advanced language proficiency. In H. Byrnes (Ed.), Advanced Language Learning: The contribution of Holliday and Vygosky. New York: Continuum, 95-108.

Tang, G. M., \& Tithecott, J. (1999). Peer response in ESL writing. TESL CANADA JOURNAL, 16, 20-38. https://doi.org/10.18806/tesl.v16i2.716

Torwong, P. (2003). Peer Response Technique: A Proposed Model for EFL Writing (Unpublished PhD. dissertation). Suranaree University of Technology.

Tosuncuoglu, I. (2019). Reflective learning views of students, Teachers and Instructors: A mixed-methods study. English Language Teaching, 12(3), 200-2013. https://doi.org/10.5539/elt.v12n3p200

Tsui, A. B. M., \& Ng, M. (2000). Do secondary L2 writers benefit from peer comments? Journal of Second Language Writing, 9(2), 147-170. https://doi.org/10.1016/S1060-3743(00)00022-9

Tudor, I. (1996). Learner-centeredness as a Language Education. Cambridge: Cambridge University Press.

Van Zundert, M., Sluijsmans, D., \& Van Merriënboer, J. (2010). Effective peer assessment processes: Research findings and future directions. Learning and Instruction, 20, 270-279. https://doi.org/10.1016/j.learninstruc.2009.08.004

Wanchid, R (2009). The Effects of Using Peer Feedback through Email with Students of Limited English Proficiency in an EFL writing class. An international conference on language, Penang, Malaysia, 27-28 May, 2009.

White, A. S., \& Caminero, R. (1995). Using process writing as a learning tool in the foreign language class. The Canadian Modern Language Review, 51(2), 323-329. https://doi.org/10.3138/cmlr.51.2.323

White, R., \& Arndt, V. (1991). Process writing. London: Longman.

Williams, K., \& Williams, C. (2012). Five key ingredients for improving student motivation Research in Higher Education Journal. Retrieved from ttp://www.aabri.com/manuscripts/11834.pdf

Yu, S., \& Lee, I. (2016). Peer feedback in second language writing (2005-2014). Language Teaching, 49(4), 461-493. https://doi.org/10.1017/S0261444816000161 
Zhu, W., \& Mitchell, D. A. (2012). Participation in peer response as activity: An examination of peer response stances from an activity theory perspective. Tesol Quarterly, 46(2), 362-386. https://doi.org/10.1002/tesq.22

\section{Copyrights}

Copyright for this article is retained by the author(s), with first publication rights granted to the journal.

This is an open-access article distributed under the terms and conditions of the Creative Commons Attribution license (http://creativecommons.org/licenses/by/4.0/). 